\title{
The Uncinate Bulla
}

\author{
By \\ E. GUMUŞBURUN ${ }^{1}$, M. AYKUT' ${ }^{2}$, S. MUDERRIS ${ }^{3}$ and E. ADIGUZEL ${ }^{4}$ \\ ${ }^{1,4}$ Department of Anatomy, Faculty of Medicine, Cumhuriyet University, 58140 Sivas, Türkiye \\ ${ }^{2.3}$ Department of Otorhinolaryngology, Faculty of Medicine, Cumhuriyet University, 58140 Sivas, Türkiye \\ - Received for Publication, January 5, $1995-$
}

\begin{abstract}
Key Words: Uncinate bulla, pneumatized uncinate process
Summary: In this study a total of 175 coronal CT scans of the nasal cavity and paranasal sinuses have been investigated. The uncinate bulla was detected in 21 (11 male and 10 female) cases of 175 patients. Out of 21 , 17 were bilateral while 4 were unilateral. The incidence of the uncinate bulla was found as $12 \%$.
\end{abstract}

The uncinate process projects from the ethmoid bone to the ethmoidal process of the inferior nasal concha (Mafee, 1991; Williams, 1989) and helps in the closure of the opening of the maxillary sinus (Kuran, 1983; Romanes, 1981). The uncinate process bounded the infundibulum medially and the hiatus semilunaris inferiorly (Zinreich, 1987) (Fig. 1). Pneumatization of the uncinate process is called the uncinate bulla as an anatomic variation (Bolger, 1991) (Fig. 2). The detailed knowledge of the uncinate bulla can be obtained after using coronal CT (Bolger, 1991; Kennedy, 1988) because it cannot be seen by the direct and Waters radiographies.

In this study, the incidence of the uncinate bulla was investigated and relevant literature reviewed and compared.

\section{Material and Method}

A total of 175 coronal CT of the nasal cavity and paranasal sinuses were analysed. All the patients had the symptoms of chronic sinusitis. Scans were reviewed for the presence of an uncinate bulla. The age and sex of the patients and the diagnosis made at the time of the imaging were recorded. CT slices were performed at $4 \mathrm{~mm}$ intervals using the Toshiba 60 AX system (Table 1).

\section{Results}

The mean age of the patients was 33.4 years (range 15-64). The uncinate bulla was detected in 21 ( 11 male and 10 female) cases of 175 patients (103 males and 72 females). Of these $21,4(2.3 \%)$ were unilateral while $17(9.7 \%)$ were bilateral (Fig. 3, 4).

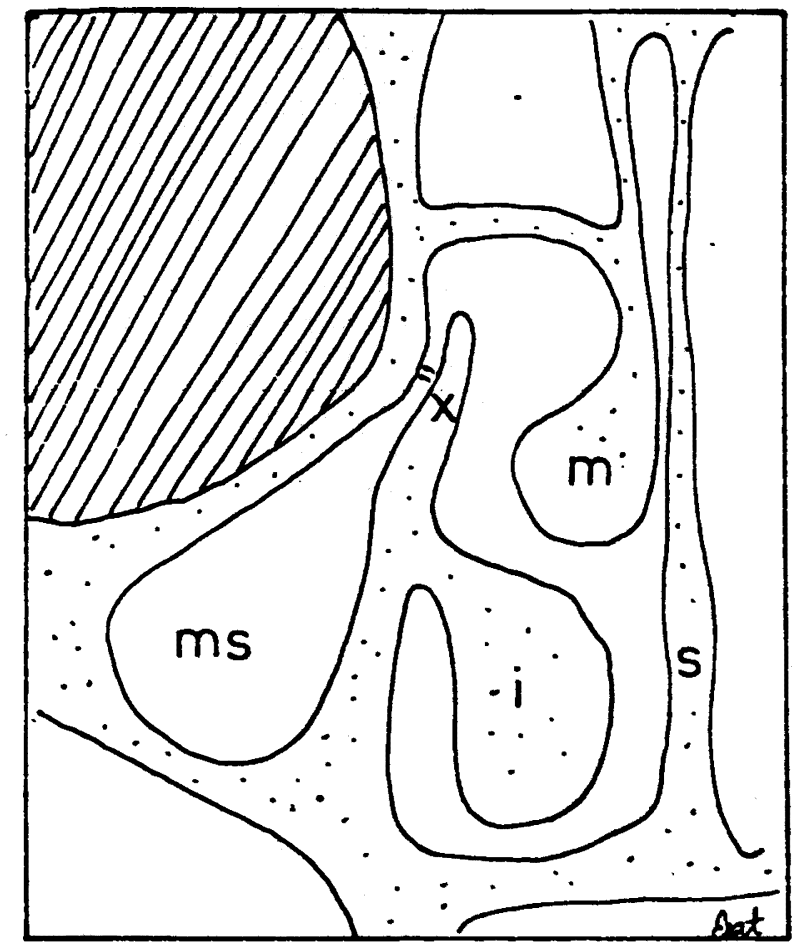

Fig. 1. The normal anatomy of the cavum nasi in the coronal plane. (ms) maxillar sinus, (m) middle concha, (i) inferior concha, (,) infundibulum, (x) uncinate process.

Mailing Address: Associate Prof. Dr. Erdem Gumuşburun, Department of Anatomy, Faculty of Medicine, Cumhuriyet University, 58140 Sivas-Türkiye 


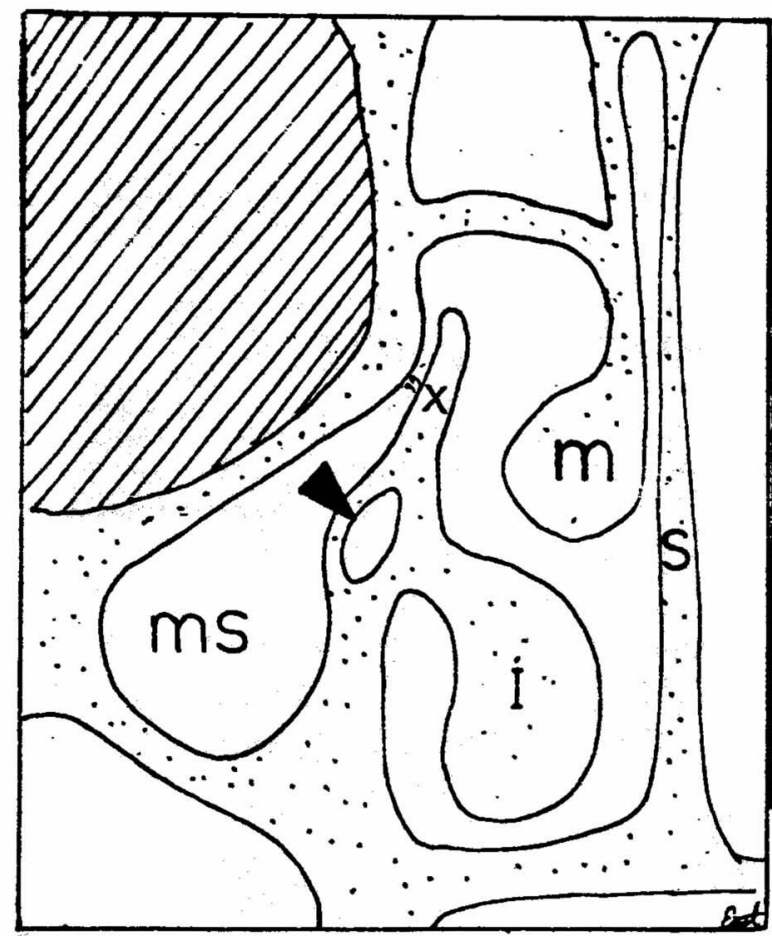

Fig. 2. A coronal view shows the uncinate bulla and other structures of the cavum nasi. (arrow) uncinate bulla, (ms) maxillar sinus, (m) middle concha, (i) inferior concha, (s) septum nasi, (,,) infundibulum, (x) uncinate process.

Table 1. CT Protocol

$\begin{array}{lll}\text { Patient position : } & \text { Head hiperextended, pron position. } \\ \text { Slice thickness }: & 5 \mathrm{~mm} \\ \text { Slice interval } & 4 & 4 \mathrm{~mm} \\ \text { Table position }: & \text { Coronal } \\ \text { Scan area } & \text { Between glabella-dorsum sella } \\ \text { Dose parameters: } & 120 \mathrm{kVp}, 400 \mathrm{mAs} \\ \text { Scan time } & 4 \mathrm{sn} \\ \text { Window setting : } & \text { Window width } 800-1000 \mathrm{H} . \ddot{\mathrm{U}} \\ & \text { Window length } 0-50 \mathrm{H} . \ddot{U}\end{array}$

The incidence of the uncinate bulla was $12 \%$. Distribution of other variations in 21 cases with the uncinate bulla was given Table 2 .

\section{Discussion}

The knowledge of the anatomy of the lateral wall of the nose has improved since the advent of functional endoscopic sinus surgery and coronal computed tomographic (CT) imaging. Agger nasi cells, Haller cells, paradoxically bend middle turbinate, concha bullosa, enlarged ethmoidal bulla, uncinate bulla and secondary middle concha are recognized as anatomical variations on CT scans (Aykut, 1994; Bolger,

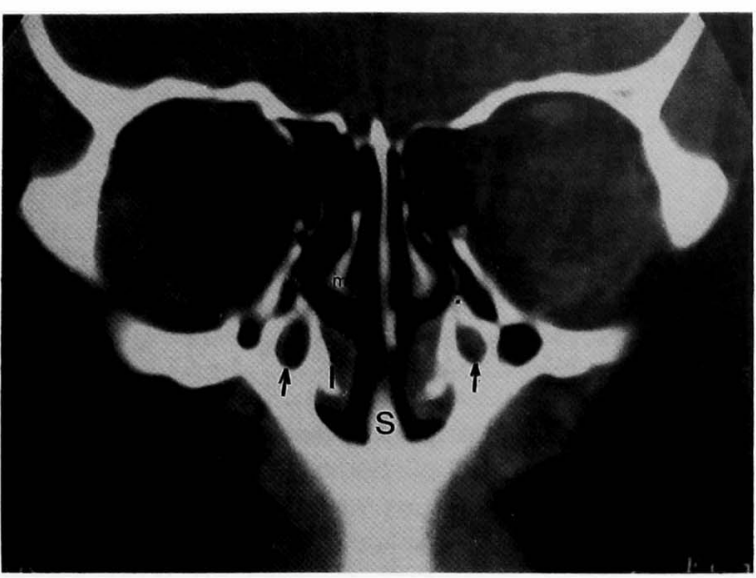

Fig. 3a. Direct coronal CT view of the uncinate bulla.

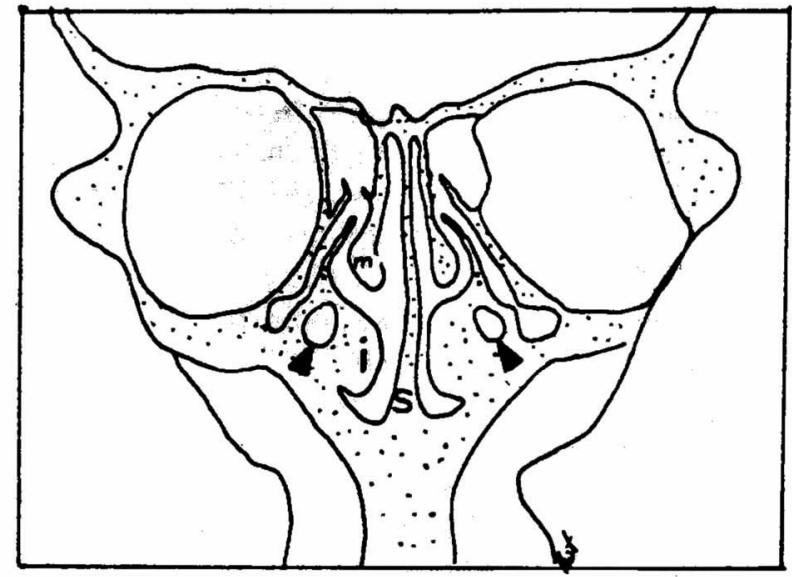

Fig. 3b. The schematic drawing of the same view. (arrows) uncinate bulla, (..) uncinate process, (m) middle concha, (i) inferior concha, (s) septum nasi.

1991: Calhon, 1991; Khanobthamckai, 1991; Lloyd, 1990). Clinically, these anatomic variations are important, owing to their negative influence on sinus ventilation in selected cases of recurrent sinusitis and headaches (Stammberger, 1988).

In this study, the observed incidence of the uncinate bulla was $12 \%$. This was noted by Kennedy and Zinreich (1988) as $0.4 \%$ and by Bolger et al. (1991) as $2.5 \%$. The cause of the higher incidence in our study may be that all cases had symptoms of chronic sinusitis.

The bulla uncinatus occurs due to excavation of the agger nasi cell into the most anterior-superior region of the uncinate process (Bolger, 1991). Pneumatization in this region potentially could impair the ventilation of the frontal sinus and ethmoid infundibulum, and hence the maxillary and anterior ethmoid sinus regions, might be expected in such cases 


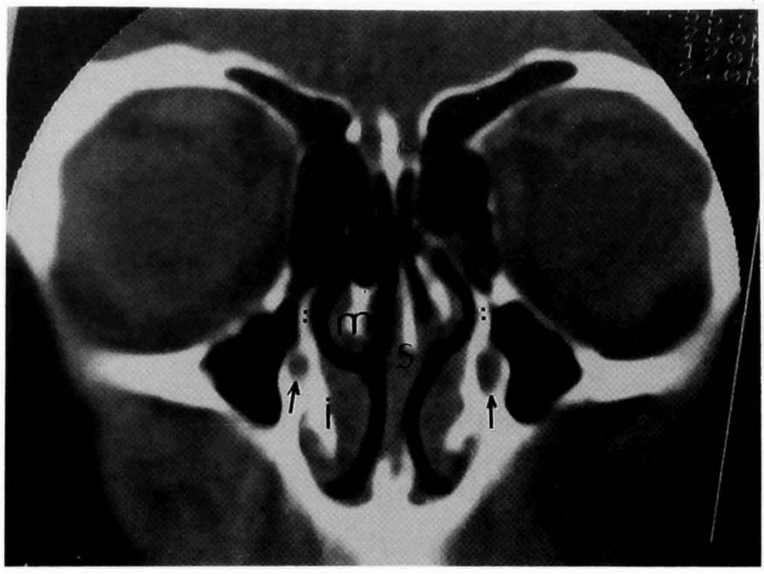

Fig. 4a. Another coronal CT view of the uncinate bulla.

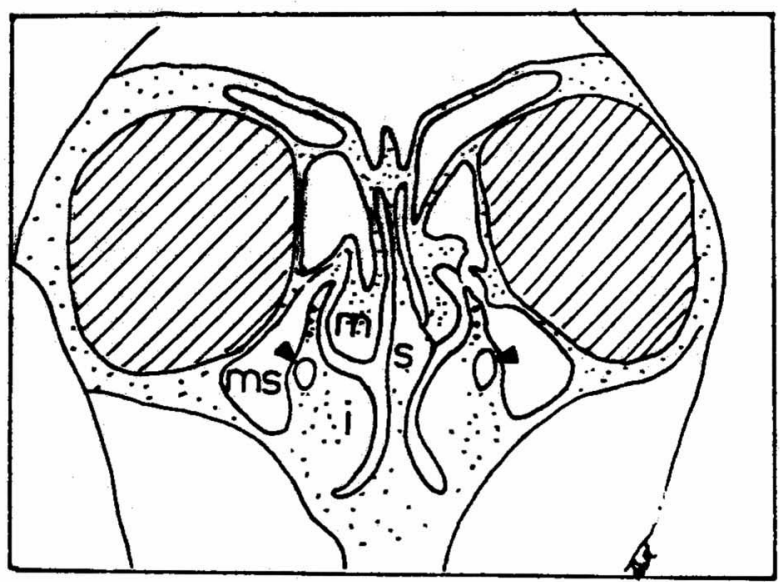

Fig. 4b. The schematic drawing of the same view. (arrows) uncinate bulla, (..) uncinate process, (m) middle concha, (i) inferior concha, (s) septum nasi.

Table 2. Distribution of other variations in 21 cases with the uncinate bulla

\section{Variations}

Haller cells

Agger nasi cells

Concha bullosa

Enlarged ethmoid bulla

Tuberculum septi posterior

Curved uncinate process

Paradoxially bend middle turbinate

Secondary middle concha

UL: Unilateral, BL: Bilateral

$\begin{array}{cr}\text { Number of cases } \\ \text { UL } & \text { BL } \\ 5 & 7 \\ 8 & 4 \\ 13 & 4 \\ 10 & 5 \\ 1 & - \\ 1 & 2 \\ 5 & - \\ - & 2\end{array}$

(Bolger, 1990).

\section{References}

1) Aykut M, Gümüşburun E, Müderris S, Adıgüzel E. The Secondary Nasal Middle Concha. Surg Radiol Anat 1994; 16:307-309.

2) Bolger WE, Butzin CA, Parsons DS. Paranasal Sinus Bony Anatomic Variations and Mucosal Abnormalities: CT Analysis for Endoscopic Surgery. Laryngoscope 1991; 101:56-64.

3) Bolger WE, Woodruff W, Parsons DS. CT Demonstration of Pneumatization of the Uncinate Process AJNR 1990; 11:552.

4) Calhoun $\mathrm{KH}$, Waggenspack GA, Simpson JB, Hokanson JA, Bailey BJ. CT Evaluation of the paranasal sinuses in symptomatic and asymptomatic population. OtolaryngologyHead and Neck Surgery 1991; 104:480-483.

5) Kennedy DW, Zinreich SJ. The functional endoscopic approach to inflammatory sinus disease: current perspectives and technique modification. Am J Rhinol 1988; 2:89-96.

6) Khanobthamchai $K$, Shankar L, Hawke M, Bingham B. The Secondary middle turbinate. The Journal of Oto Laryngology 1991; 20:412-413.

7) Kuran O. Sistematik Anatomi, Istanbul: Filiz Kitabevi, p 14, 1983.

8) Lloyd GAS. CT of the paranasal sinuses: Study of a control series in relation to endoscopic sinus surgery. The Journal of Laryngology and Otology 1990; 104:477-481.

9) Mafee MF. Endoscopic sinus surgery: Role of the radiologist. AJNR 1991; 12:855-860.

10) Romanes GJ. Cunningham's Textbook of Anatomy, 12th Ed, Oxford: Oxford University Press, p 124, 146, 1981.

11) Stammberger $\mathrm{H}$, Wolf $\mathrm{G}$. Headaches and sinus disease: the endoscopic approach. Ann Otol Rhinol Laryngol Suppl 134P, 3-23, 1988.

12) Williams PL, Warwick R. Grayn's Anatomy, 36th Ed, Edinburg, Churchill Livingstone, Edinburgh, London, Melbourne, New York, p 367, 1989.

13) Zinreich SJ, Kennedy DW, Rosenbaum AE, Gayler BW, Kumar AJ, Stammberger H. Paranasal sinuses: CT imaging requirements for endoscopic surgery. Radiology 1987; 163:769-775. 